\title{
Quality of Streets - Quality of Urban Life: \\ A Case Study of Tanta City, Egypt
}

\author{
Engy H. Saeed \\ Assistant Prof, Architecture engineering \\ department, engineering Faculty, Tanta \\ University, Egypt \\ engy_hassan@f-eng.tanta.edu.eg
}

\author{
Nermeen A. Omar \\ Assistant Prof, Architecture engineering \\ department, engineering Faculty, Tanta \\ University, Egypt \\ nermeen_omar@f-eng.tanta.edu.eg
}

\begin{abstract}
Street plays an important role in the built environment as it is the main spine for activities, movements, and social interactions in every city that affects the people's quality of life (QoL). Recently the quality of urban life (QoUL) becomes a concept that has been discussed in various studies as a response to many problems facing the city streets. However, most streets are designed now for vehicle movements rather than for all users' needs and values. In this context, the research aims to activate the street's role that achieves the quality of urban life (QoUL) for all users through focusing on the review of the trends and the approaches of urban design and the displays of the quality of urban life definitions and its indicators. To these ends, the research sets a proposed list of urban quality indicators as a guideline framework to assess street performance. Therefore, in the analytical study, the research chooses one street in Egypt then applies the proposed quality indicators framework to assess the street quality. The research concludes the important role of the indicators of the urban quality of life: social, physical, environmental, economic, visual, and management indicators to achieve the street quality.
\end{abstract}

\section{KEYWORDS}

Quality of life; urban quality of life; new urbanism; indicators.

\section{INTRODUCTION}

The needs and values of the human have an essential impact on the urban studies to achieve the quality of life, which is being widely accepted as an essential element of sustainability and livability (Fahy, 2006). Consequently, the role of the designers and urban planners is to accommodate these needs and values to provide the most suitable, enjoyable, and comfortable city.

The urban fabric of any city consists of building and spaces; the streets are considered the main ratio of these spaces. Thus, the streets and their sidewalks are considered the vital elements in the city that are the valuable assets where all activities, movements, and individuals' intersections have been occurred. Also, it reflects the image, the culture and the identity of the city (Moghtic, 1992). Recently, the urban design and planning of the streets have given a priority to the vehicles movements disregarding the needs and human dimensions of all users. This results that street, as movement corridor, ignore achieving the environmental, economic, social and aesthetical qualities. This ignorance produces negative effects on urban streets development such as environmental 
degradation, insecurity, and traffic congestion that led to low urban quality of life. Therefore, there are many reviews and studies appear such as ABCs, UN, New Urbanism, and smart Growth trends. These trends focus on the human dimensions in the urban design and planning. In addition, trends aim to the rehabilitation of the streets, considering them as the most vital organs and main public places of the city (Montagomry, 1998). This reinforcement is the important role of the streets design to achieve the urban quality of life.

The aim of this research is to assess the quality of streets through developing a proposed framework that sets guidelines indicators to enhance the urban quality of life through a review of studies that concern the streets, the new trends in urban design, and display the urban quality of life and its indicators.

The research methodology is based on two approaches: firstly, the theoretical one is studying the urban quality of life (definition - indicators) and reviewing the new urban design trends. These studies led to setting a guideline framework checklist to assess the street performance, secondly, the analytical approach which analyses a case study concluding a guideline of new trends urban design of the street. Finally, the research suggests the development recommendations of the selected case study.

\section{QUALITY OF LIFE}

The concept "quality of life" (QoL) becomes an international issue because of many problems which facing the cities all over the world. The term quality of life has been disused in many researches and has a wide range of interest from designers and planners in recent years. The concept of QoL is multidimensional and multi-scale concept .There are various fields which are interesting of the quality of life such as urban development, human wellbeing, health care, education, built environment, leisure, recreation, social science, and political science...etc.(Mostafa, 2012) most literature and reviews show that there are broad variety of approaches and models within the field of QoL and environmental quality, these also discuss the relationship between QoL and public good.(Mitchell, 2000) QoL has been defined from different theoretical perspectives, there is a wide agreement that the term QoL is used to refer to human well-being (Ott, 1978), and life satisfaction that come from having good health, comfort and good relationships (Diener \& Suh, 1997), and it is an individual's perception and assessment of his own position in the culture context (WHO, 1993).

It is also referring to satisfaction of people about the fulfilment of their important needs and values (Diener, et al 1999), and how these needs are met. it is worth to be mentioned that the concepts sustainability, and livability are related to the concept of QoL, many reviews and literatures developed models describing the livability and sustainability as an interaction between physical, social, and economic aspects (Kamp, 2003), (Dashora, 2007), (Serg El Din, 2013), and also these three aspects have been used to conceptualize QoL concept. Thus, achieving both sustainability and livability leads to achieve QoL. 


\section{QUALITY OF URBAN LIFE (QOUL)}

Quality of urban life (QoUL) becomes a complex concept related to the urban and environmental quality. The QoUL is considered very important and vital because of the importance of urban environment for other aspects of life and the effect of its conditions on people's quality of life. Therefore, it is clear that quality of urban environment refers to the person-environment relationship and it is related to the environment from the perspective of persons (Cummins, 2000- Marans, 2000). Recently, it was recognized that urban quality is an essential part of concept of QoL (RIVM, 2001). This concept is supposed to give a sense of well-being and satisfaction to its users. Satisfaction is viewed as a sum of satisfaction with different environmental aspects (cambell, 1976). Also, urban environmental quality is a result of quality of the parts that composed the given location as (nature, built environment, open spaces, infrastructure, natural resources...etc.), but more than the sum of components of its parts (Kamp, et al, 2003- Frick, 1986). Therefore, the urban and environmental quality has a positive influence effect on people's sense of quality of life. Furthermore, it is related to the most of aspects of urban life (safety, health, leisure, social connection.....etc.) and it is the most important mean for enhancing the quality of urban life.

There are studies and movements which are interested in the QoL in the urban context, the most important movements is New Urbanism which is a movement to reshape or redesign any built environment, it is considered the most important trend which concentrated on achieve the quality of life by make a better places for users on all levels from cities to neighborhoods. New Urbanism has many principles which can applied at all levels from one building to the hole community; walkability, connectivity, mixed-use, mixed housing, quality of architecture \& urban design, traditional neighborhood structure, smart transportation, sustainability, and quality of life (newurbanism, 2018)

Another important movement that concerned of studying the QoL with the urban is the Smart Growth which interested in development the economy, the community and the environment. The Smart Growth includes many principles such as; improve QoL, transportation variety, housing choices, conserve natural \& cultural resources, social equity, sense of community \& place, and promote public health (smartgrowthamerica, 2018).

The Quality of urban life is determined by both objective and subjective indicators. (Robert, 2007) The Objective indicators which may affect group people who mutual common perception about their living status as a person's experience of life (Dashora, 2007). These indicators generally focus on social, economic, health, and physical indicators. While the subjective indicators identified by studying the user's level of happiness, pleasure, and satisfaction as a result of interaction with their urban environment. Most literatures argue that objective and subjective indicators are essential in studying the person-environment relationship and to get complete perception and better understanding for urban quality of life. So, the integration of the objective and subjective indicators is preferable to assessment process. (Robert, 2007- Kamp, 2003). 


\section{QUALITY OF URBAN LIFE INDICATORS}

The Quality of urban life Indicators are considered highly important to express the human life. It is generated from the human needs and values (Robert, 2007). Therefore these indicators are a tool for assessment the QoUL in the urban area.

Over the past quarter century, many researches, reports and projects that interesting in the quality of life in cities, neighborhoods and urban context are identified many and various indicators or dimension which are believed to be reflect the quality of urban life (Turkoglu, Marans 1993- Elnaz, Razaghi,2017). The selection of indicators is a complex process, there is no global method or techniques are available for indicators selection (Malczewski, 1999). Therefore the main goals of the research or project play an important role in indicator selection process. (Cicerchia, 1999).

In recent years, a number of QoUL studies in cities have developed indicators programs which main objective was measuring the quality of urban life. Some programs used both objective and subjective measures to assess the quality of urban life, and some programs have been guided by theories which are resulted from academic researches. A major research programs started in united states of America then extended to many world cities was lunched by Detroit Area Study (DAS) (Marans, Couper, 2000) the research program measure the quality of urban life in many cities around the world from covering objective condition of urban environment and behavioral aspects of urban living. There are also many researches, reports, guidelines, and case studies in QoUL field as QoL project in New Zealand reported in 2007, which covers 68 key indicators under economic, social and culture, physical and environment domains. The Project in (USA) jakson ville, Florida in 1986 defined the QoL as an external environment which is divided into 9 factors: economic, political, environmental, health, education, social, culture, recreation, public safety and transport. (RIVM, 2001). The report of QoL in city of Winnipeg, Canada which explained the QoL indicators in different dimensions of QoL that related to social, economic, and physical aspects of urban areas. (Hardi, Pinter, 2006). The guidelines of United Nation Human Settlement program (UNCHS): economic development, social development, shelter development, environmental management and governance (UNHABITAT, 2008). Study of (Mitchell, 2000) whish presented all attribute of the environment and characteristic of people are related to the person-environment relationship, QoL components: health, physical environment, security, personal development, natural resources, community development, goods and services.

\section{Quality of streets}

The streets are the most fundamental physical elements of the urban context. They represent about $20 \%$ of all development urban land (ITDP, 2011). Streets are considered as a container of multi functions of any public life. Streets are vary in scale function and purposes, they have many integrated functions as social, economic, cultural, environmental function as well as their function as a link between urban areas.

The street is more than public utilities and not only a means of access but also an area for social expression, and public spaces. It is a place where people walk, shop, meet, and 
engage in many social and recreation activities that make urban living enjoyable (Dumbaugh, 2005). On the other hand, it has an important public realm function which should reflect the need of persons who use it. Jacobs, cook (1980), Gehl (1989) and others argue that successful urban places are based on street life (Montagomry, 1998).

However, recently over the latter half of the 20th century, the design of the streets has been dominated by the need of motorized transport. The great increasing of number of private vehicles and high density of traffic convert the purpose of the street to conducts for the automobiles movement. Although the importance of the streets as a movement path which allows to reach the wanted place especially in bad weather or access to the buildings mostly the disabled users or to reaching the public transit and adding more surveillance in the street (Duffield, Byrne, 2010). But it is important to design the street for more purposes and considers it as a place of human activity which different according to the urban context whether for pedestrians, cyclists, public transit users and drivers who use many parts of the street. So, the imperfection of the street role as a public space effects negatively on the quality of life and there is an imperative need to look at streets as links and places (Jones, et al 2008-Lahart, et al, 2013).

The street is considered as the key of the quality of the public realm. Good, better designed streets contribute greatly to the quality of the built environment, and play a significant role in creating sustainability and livability in street life (Bevan, et al, 2007) which occupied many parts of street whether; at the edge of the street, the integrated space between the side walk and the access of the street boundaries buildings, the cyclists' lanes. Waiting spaces the public transit and the parking spaces or vehicles waiting (Duffield, Byrne, 1999).

\section{THE PROPOSED STREET QUALITY OF LIFE INDICATORS}

To achieve the Street Quality, there is a significant need to a holistic approach for street design process with perspective of quality of urban life, livable, and sustainable street. This approach should take a great priority to the alternative demands for users of streets including; the physical needs of the different users at all times, create attractive interesting streets, create a desirable microclimate for users, provide appropriate social interaction, provide a secure environment, making balance between users' needs and surrounding buildings uses, reinforce streets identity and culture, achieve democratic expression, infrastructure and sustainable environment.

By reviewing the previous studies and researches which interested in studying the modern trends and approaches of the urban design. And by studying the urban quality of life and its indicators, the research suggests a proposal framework assessment indicators as a guideline to enhance the urban quality of life for the streets. Figure (1).

The proposed selected indicators classified into six categories. The indicators groups are divided in to sub-indicators that correspond to detailed elements and tools of the evaluation Table (1). 
Figure (1) The proposed indicators of the quality of urban life

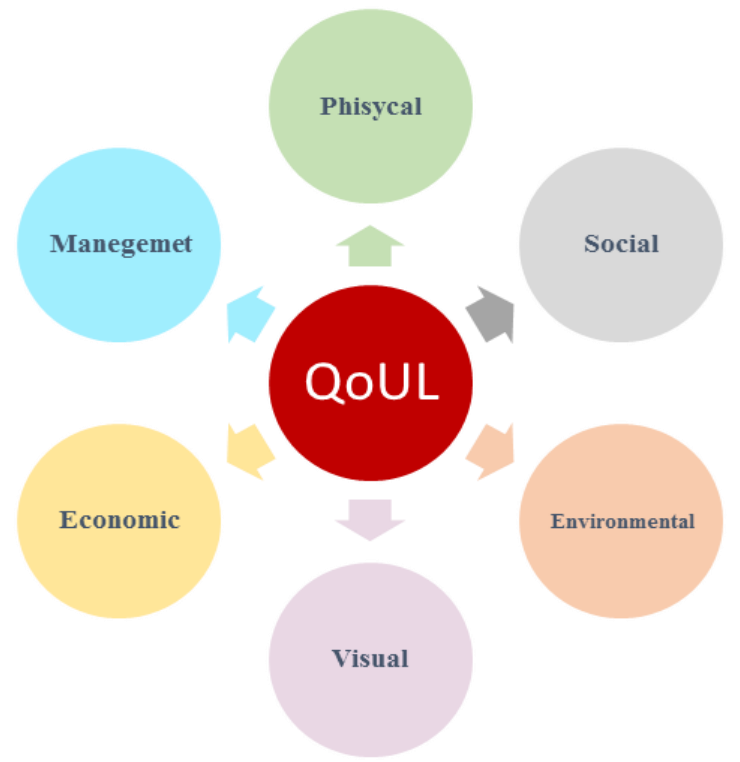

Source: authors 2018

\subsection{Physical Indicator}

\subsubsection{Mixed use activity}

The implementation of mixed use development is essential to create more sustainable communities which Provide features that support public services (Merron, et al, 2007). The choice of the street by a great variety of users; the families, children, elderly, disabled....etc. This related to the existence of different activities which located at the street space or in the boundaries buildings. These different activities can perform by various movements (vehicles, cycling, walking ...etc.) (Luo, 2002). So, the quality of the street related to the users' number and the traffic speed, beside the balance between all the street users' kinds (walking, cycling, waiting public transportation, driving, sitting, viewing...etc.) (Mahmoudi, et al, 2015).

\subsubsection{Mobility}

Comprehensive Sustainable transportation system plays a key role in quality of street for creating livable communities (Steg, Gifford, 2008), Offering a more sustainable alternative to the car to make well-connected, easily accessible transportation networks that provide comfort, safe and attractive access (Qawasmeh, 2014). Streets for all including pedestrian, cycling, people with disabilities and public transportation are improving choices for short trips, enhancing walkability, providing parking. Also, transportation support facilities affect quality of urban life, such as (transit and bus stations, parking, traffic signs...etc.) (Gehl architects, 2009).

\subsubsection{Security}

Security is essential for every sustainable space by achieving its implicit in all levels of design and planning of the street. Street security can accomplish by traffic, crime and 
violence protection, these can be reach by dividing between various movement in the street by using the landscape elements, and by surveillance on the street all time (Luo, 2002).

\subsubsection{Orientation}

Touring through streets is depending on directions using distances and organized places. The orientation makes users more certain about their destinations and feels safe till reach them. It links to sanity and survival (Lynch, 1960). So, it is important for users to recognize the street including its barriers, distances, intersections and directions. All this with the help of many elements such as signs, posts and landmarks (Luo, 2002).

To reach orientation there are many elements such as: Information elements such as maps, signpost, street name.... etc. Physical elements such as landmarks which include important buildings, signs, social and culture cues (Amos, 1977). These elements with the mental maps of users will guiding them to choose the short distance, least effort and viewing destination.

\subsubsection{Connectivity}

The good access street physically means a good, safe and flexible network which offers many choices for users to take different destinations (Luo, 2002). Beside choose the suitable mode of movement (walking, cycling, driving, public transit). It can be achieved by the planning of the street through the block size, street pattern and the grain texture (Yasaman, 2016).

\subsection{Social Indicators}

\subsubsection{Accessibility}

The accessibility is the ability of all users to reach easily and access all the facilities to get their needs. The accessibility can reached by the permeability which allows users to choose how they move through the city and making it a resilience moving from one street to another without any interruptions (Luo, 2002). This accessibility can affect the level of activity, the density and the security (Yasaman, 2016).

\subsubsection{Equity}

It means the same opportunities, possibilities, and rights to every user. The social and economic relationship should be ruled by principles of efficiency and effectiveness (Serg El Din, 2013). Also, by providing equal access to economic activities, services and facilities (Harang, 2003). Design of street should consider all kinds of users; gender, culture, ages, ability and incomes.

\subsubsection{Social relationship}

Healthy social interaction is very important and vital to general well-being for users. Because of that the design of street should provide spaces in which users can socialize and gather (Harang, 2003). Every street may be considered as a place for many activities which reinforces the social relationships in it such as conversation, recreation, entertainment and making ceremonies (Luo, 2002). Some activities and addition 
elements may provide to encourage the interaction between community members such as (chairs, tables, gardens, courtyards, game rooms....etc.) But it could inhibit specific activities because of the lack of space in street or the landscape elements (Moghtin, 1992). This changes enhancing the sense of community, sense of pride and belonging and create livable, pleasant streets. Thus, the implementation of mixed use development, public transit system, and increase walkability will also encourage more interaction among the member of community (Harang, 2003).

\subsubsection{Safety and Comfort}

It is very important factor to assess quality of urban life. Strong sense of community and belonging can result in safer, secure streets. Psychologically, the need for safety in any urban context may be away from the bodily harm (like vehicles accidents), need to sense of the place geographically and socially, and need to sense saving by knowing all the surroundings socially and physically (Rudlin, Falk, 1999). There are many feature and urban treatment to enhance the sense of safety in streets such as; separated paths for every movement, activities and users including pedestrians, cycling, vehicles and vendors and by choosing the suitable landscape elements for these movements. Taking in consider; the presentence of function and activities day and night, provide clear views from inside to surrounding out said, change the circulation patterns to provide better traffic flow, get rid of blind corners which get chance to hiding places for criminals (Toronto Public Health, 2014) and having a comfortable and easy daily life make people feel safe and comfortable in attractive and functional surrounding (Gehl architects, 2009).

\subsubsection{Privacy}

Having opportunity to be yourself to do your own things and having a place of your own. Privacy is the organization of the contact with the surroundings which is different depending on the culture, age, social statues...etc. The privacy as Jon Lang has four types: solitude, intimacy, anonymity, reserve (Darhl, 1997). Users can get privacy out of the territories whether perceived one such as the change of surface materials and patterns and the building types, or physical one like walls, gates, fences and trees...etc. So, any open space such as street can divided according to privacy and activities to public, semipublic, semi-private and private space.

\subsubsection{Sense of place}

Generating and protecting sense of place is very important to establishing a unique identity. It is essential to a richer and fulfillment environment. According to (Relph, 1976Canter, 1977) and other by the components of sense of place and the relationship between three essential elements: physical space, activities and sensory experience (Montagomry, 1998). Sense of place mainly recognized through distinguish local environment; strong relationship between the street and the buildings that frame it; encourage social activity; visual quality; good choices of street scape and furniture, planting, respect for historic aspects, and surface materials. (Merron, 2007) 


\subsection{Visual Indicators}

\subsubsection{Legibility}

The clearness of the way where users moved in, this can achieve by recognized and reading the urban context of the street (buildings and spaces) whether for walking or driving users(Rudlin, 2013), it refers to how it is easy to understand the street and provide a sense of location (Yasaman, 2016). The legibility can be supported by many elements such as landmarks which oriented the users.

\subsubsection{Attractiveness and Aesthetics}

Attractiveness is the way to make the street more interest and motivating, this sense can be reached by considering the human scale, texture, proportion...etc. (Moghtin, 1992). These principles should be applicable not only on the boundaries of the street but also on the space of the street and the landscape elements in it. All these elements should be essentially designed to enhance the visual image (Rehan, 2013- Gehl architects, 2009).

\subsubsection{Fine grain}

Urban grain fabric has deep effects on the city function which influences on the users life. Fine grain consists of many small blocks with in each block number of buildings with narrow façade. This produces more intersections which make traffic slower and safer, also the relations between buildings and the street, also its style, type, access and activity in it, impact on the grain, it provides walking, working, meeting built environment. So the fine grain makes street pattern easily navigable and makes a feel of superior and enjoyable for the street users. It also offers many opportunities for discovery and exploration (Gehl, 1987- Artibise, 2012, Konkol, 2015).

\subsection{Environmental Indicators}

\subsubsection{Health}

The street faces many vital standards of health such as clean air, low level of noise, low level of pollution, Cleanliness and healthy life style. According to RIVM, 1991 the environmental pollution influences on public health considered small when it is compared to the influence of life style (Poll, 1997). Thus, street enhances healthy lifestyle by encouraging people to walk and cycle for improving their health and reducing motor traffic pollution and energy use and provide appropriate ways to control and manage wastes. In addition, providing public green space and water elements is very important to filtering the noise, light and air of the street and contributes to achieve the psychological comfort for the users of streets (Kladivo, Halás, 2012- Gehl architects, 2009).

\subsubsection{Protection}

It includes many aspects such as; the users' protection from climate effect (sun radiation, heat and wind) to achieve users' thermal comfort. Reducing the negative impacts of natural environment, saving the environmental resources, supporting the environmental biodiversity, and conserving historical and cultural context by use urban design approaches that respects historic content (Gehl architects, 2009). 


\subsection{Economic Indicators}

\subsubsection{Energy consumption}

Reduce energy consumption by supporting the non-motorized travel as bicycling and walking, enhance energy-efficient trains for people and use material and resources that need lower maintenance requirement (Bevan, 2007). The materials used in the street should be sustainable, conservative natural sources and using minimum energy.

\subsubsection{Reduce consumption of material resources}

Support using solutions that use recycled materials in construction, support design and solutions that require lower infrastructure and increase durability and lifecycle (Bevan, 2007- Rehan, 2013).

\subsection{Management Indicator}

\subsubsection{Efficiency of services}

Provide efficient urban maintenance services in street elements such as; pavements, lightings, seats....etc. which ensure the sustainability and continuance of quality of urban life in the streets (Garau, Pavan, 2018).

\subsubsection{Coordinate management}

Use a holistic approach that Identify and counsel stakeholders responsible for the excellence maintenance and the management of streets at an early stage to ensure integrated urban management and achieve high quality outcomes (Merron., et al.,2007).

\subsubsection{Community involvement}

Considering the community as a partner in management their streets who have a vision for the improvement of streets. They participate in local governance which increases the sense of ownership and pride (Merron. et al., 2007). 
Table (1) The proposed guideline framework for the QoUL indicators of the street

\begin{tabular}{|c|c|c|c|}
\hline Indicators & Sub indicators & Tools \& eleme & \\
\hline \multirow{5}{*}{ Physical } & Mixed uses $\&$ activities & $\begin{array}{ll}\circ & \text { Varity of activities } \\
\circ & \text { Different movements } \\
\circ & \text { Slow traffic speed } \\
\end{array}$ & $\begin{array}{l}\circ \text { Public facilities } \\
\circ \text { Streetscape elements }\end{array}$ \\
\hline & Mobility & $\begin{array}{ll} & \text { Different movements lanes } \\
\circ & \text { Sustainable transportation system } \\
\end{array}$ & $\circ$ Streetscape elements \\
\hline & Security & - Division between different movements & $\begin{array}{l}\text { Streetscape : zebra line- Lighting } \\
\text { Signs }\end{array}$ \\
\hline & Orientation & $\begin{array}{ll} & \text { Landmarks : Important buildings } \\
\circ & \text { Signs } \\
\circ & \text { Maps } \\
\end{array}$ & $\begin{array}{ll} & \text { Posts } \\
\circ & \text { Street name }\end{array}$ \\
\hline & Connectivity & $\begin{array}{ll}\circ & \text { Street pattern } \\
\circ & \text { Grain texture } \\
\end{array}$ & $\begin{array}{ll} & \text { Block size } \\
\circ & \text { Multi choices movements } \\
\end{array}$ \\
\hline \multirow{6}{*}{ Social } & Accessibility & $\begin{array}{ll}\circ \text { Varity of activities } \\
\circ \text { Hierarchy of the street } \\
\end{array}$ & $\circ$ Streetscape elements \\
\hline & Equity & $\begin{array}{l}\text { Different movements for different users' } \\
\text { kinds }\end{array}$ & ${ }^{\circ}$ Different streetscape elements \\
\hline & Social relationship & $\begin{array}{ll}\circ & \text { Setting \& activities spaces } \\
\circ & \text { Walkability } \\
\end{array}$ & $\begin{array}{ll}\circ & \text { Public transit system } \\
\circ & \text { Streetscape elements } \\
\end{array}$ \\
\hline & Safety \& comfort & $\begin{array}{l}\text { Varity of activities and uses day \& night } \\
\text { Clear views }\end{array}$ & $\begin{array}{lll} & \text { Attractive \& function } \\
& \text { surroundings } \\
\circ & \text { Street scape elements } & \\
\end{array}$ \\
\hline & Privacy & $\begin{array}{ll} & \text { Dividing movements types } \\
\circ & \text { Dividing spaces by Materials change } \\
\circ & \text { \& Buildings types } \\
\end{array}$ & $\begin{array}{l}\text { Using walls. Gates, fences...etc. } \\
\circ \text { Street scape elements }\end{array}$ \\
\hline & Sense of place & $\begin{array}{l}\text { Physical activities spaces } \\
\text { Street scape elements }\end{array}$ & $\begin{array}{l}\text { Sensory experience: } \\
\text { Surrounding building Character } \\
\text { distinguish local environment } \\
\end{array}$ \\
\hline \multirow[b]{2}{*}{ environmental } & Health & $\begin{array}{l}\text { Sustainable transportation system } \\
\text { - Sustainable pavement materials } \\
\end{array}$ & $\begin{array}{cr}\text { Streetscape } & \text { elements: } \\
\text { Vegetation } & \text { Water } \\
\end{array}$ \\
\hline & $\begin{array}{l}\text { Protection \& thermal } \\
\text { comfort }\end{array}$ & $\begin{array}{l}\text { Decrease negative impacts on natural } \\
\text { environment by Streetscape elements: } \\
\text { Pavement, Vegetation, Water }\end{array}$ & $\begin{array}{l}\text { conserve historical and cultural } \\
\text { context }\end{array}$ \\
\hline \multirow{3}{*}{ visual } & Legibility & $\begin{array}{ll}\circ & \text { Movement types } \\
\circ & \text { Street pattern } \\
\end{array}$ & ${ }^{\circ}$ Landmarks \\
\hline & Attractiveness & $\begin{array}{ll}\circ \text { Scale } \\
\circ \text { Texture } \\
\circ \text { Proportion } \\
\end{array}$ & $\begin{array}{ll} & \text { Colours } \\
\circ & \text { Streetscape elements }\end{array}$ \\
\hline & Fine grain & $\begin{array}{ll}\circ & \text { Intersections } \\
\circ & \text { Block sizes } \\
\end{array}$ & $\circ$ Street pattern \\
\hline \multirow{2}{*}{ economic } & Energy consumption & $\begin{array}{ll} & \text { non-motorized travel } \\
\circ & \text { lower maintenance requirement material } \\
\end{array}$ & $\circ$ Streetscape elements \\
\hline & $\begin{array}{l}\text { Reduce consumption } \\
\text { of material resources }\end{array}$ & $\begin{array}{ll} & \text { use recycled materials } \\
\circ & \text { lower infrastructure } \\
\end{array}$ & $\circ$ increase durability and lifecycle \\
\hline \multirow{3}{*}{ management } & Efficiency of services & ${ }^{\circ}$ efficient urban maintenance services & ${ }^{\circ}$ sustainability \\
\hline & $\begin{array}{l}\text { Coordinate } \\
\text { management }\end{array}$ & - Identify stakeholders responsible & $\circ$ integrated urban management \\
\hline & $\begin{array}{l}\text { Community } \\
\text { involvement }\end{array}$ & ${ }^{\circ}$ community involvement & ${ }^{\circ}$ increases the sense of ownership \\
\hline
\end{tabular}

Source: authors 2018

\section{CASE STUDY}

The aim of this part of the study is to assess the quality of urban life of a street at Tanta city, Gharbiya governorate, EGYPT by using the proposed guideline framework to improve the street as a livable and sustainable street. This can be achieved by providing social 
relationships, comfort and safety environment with various choices of movements. That sets the street as an attractive and accessible place.

The case study determines numbers of subjective and objective tools: mapping analyses, field observation by walking through assessment using the proposed guideline checklist and face to face interviews. The study chooses El- Moalemeen Club Street. It is one of the main streets in Tanta city, Gharbiya governorate, EGYPT. It starts from KafrEssam st. passing through one node to El-Gish Street which is the most important movement spine in the city. It is considered as an important street because it has multi functions aspects such as; Tanta sporting club, El-Moalemeen club, governorate mosque, international hospital and many residential and commercial buildings. All of these aspects have reinforced the street as one of Tanta's most vibrant public places Figure (2).

This section monitors the current statue of the street by using pervious tools and submits many suggestions, various elements and tools to improve the street according to the proposed indicators.

Figure (2) Location of the case study El-Moalemeen Club street
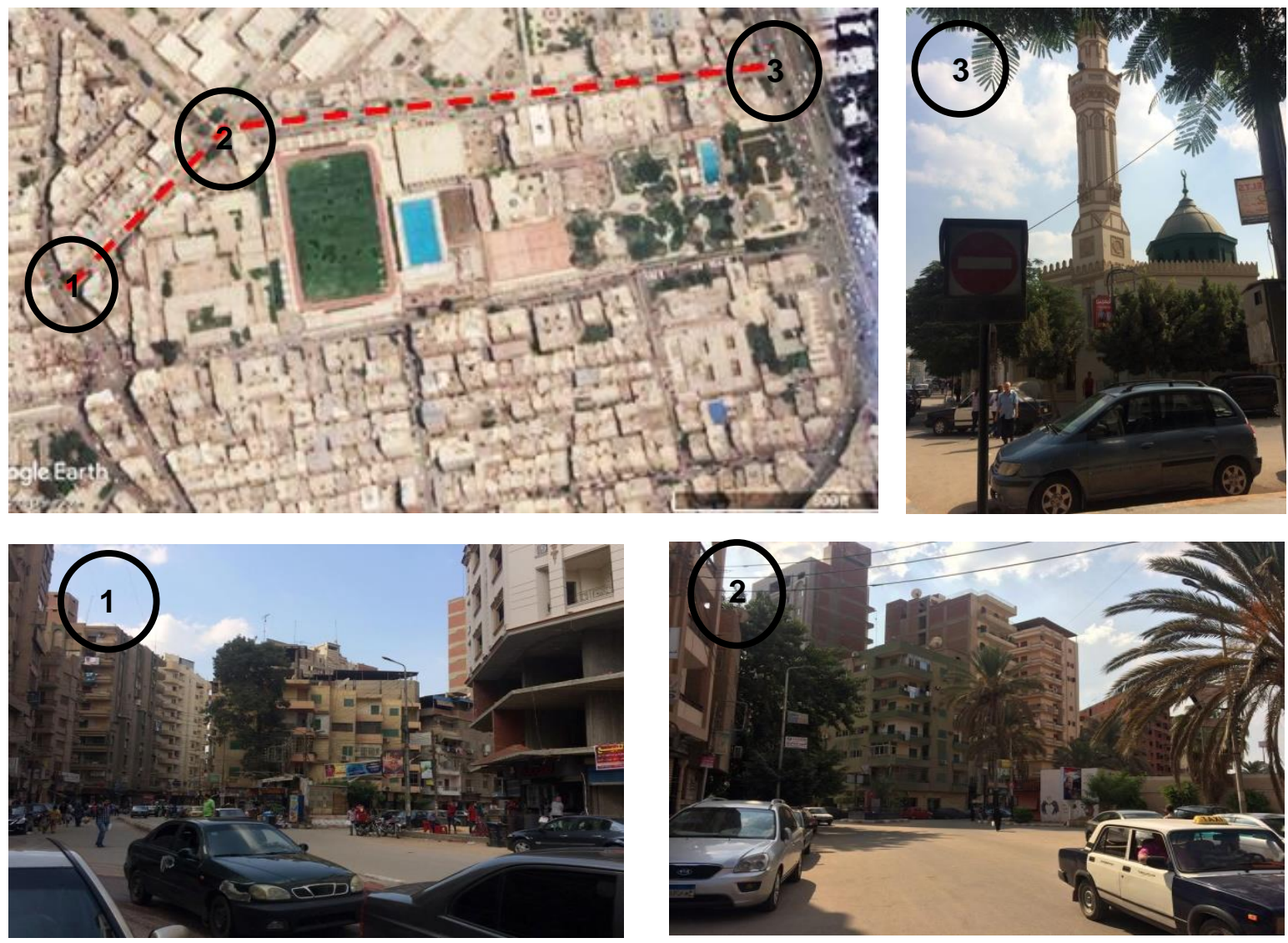

Sources: Google Earth-authors 


\subsection{Physical Indicator}

\subsubsection{Mixed uses}

The street has different uses such as residential, commercial, recreation and health uses which produced many activities with different kinds of users Figure (3). However, the street lacks the streetscape elements and the conflict between the movements in the street effect negatively on how users react with the street activities and uses. This can be improved by creating a good mix and integrated uses and activities on each side of the street. By redesign the street to make balance between all kinds of users via appropriate spaces for diverse activities with good designed streetscape. In addition, reduce the traffic volume through the street to encourage the density of the activities in it.

\subsubsection{Mobility}

There is vehicles domination with shortage of the pedestrians' sidewalks (without continuity along the street and differ width in each side) Figure (4), Figure (5) and cyclist lanes absence, beside the lack of the public transit and the street features which serve it like bus stop shelters, seats, and direction signs. The street hasn't parking area so the vehicles occupy part of the street area.

Therefore, the street needs to provide suitable lanes for different movements with a fitting division between them and suitable parking area in addition to using the proper landscape elements such as light signs, pedestrians crossing.....etc. for all users including people with disability. Moreover, design pedestrian crossing with light signs.

Figure (3) Different Activities in the street (Moalmeen club- international hospital-retails)
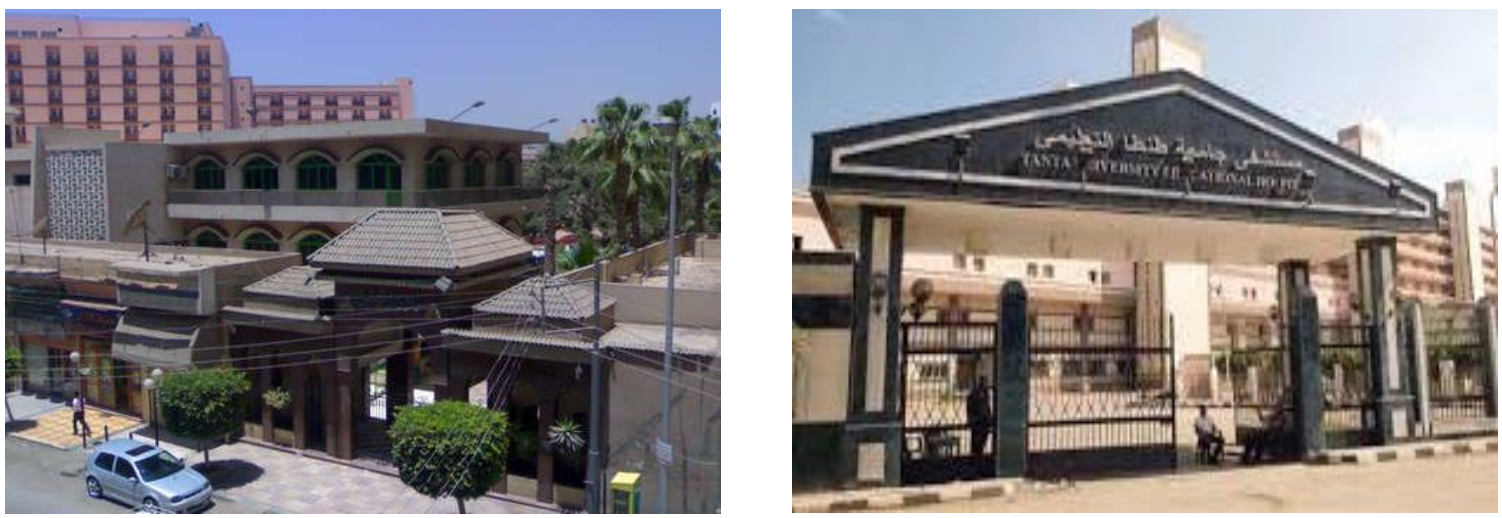

Source: authors 2018 
Figure (4) Domination of the vehicles

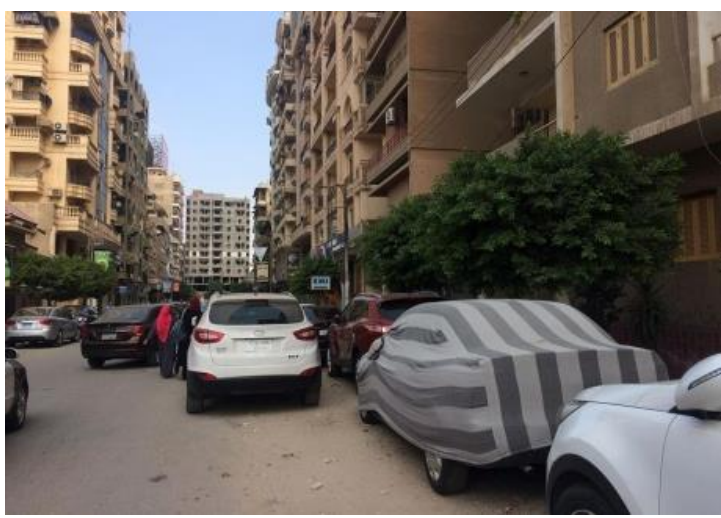

Source: authors 2018
Figure (5) No continuity sidewalks

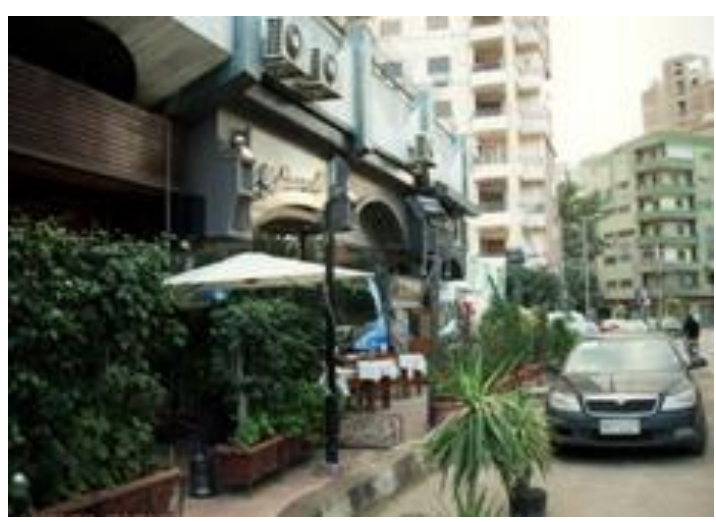

Source: authors 2018

\subsubsection{Security}

The street traffic has conflict between vehicles and pedestrian, and the absence of pedestrian crossing cause traffic accidents. In addition, there are some dark and hidden areas of street which increase crimes. This can be improved by making the street as an overlook public space and using landscape elements to; divisions the movements, provide street lighting and set direction signs.

\subsubsection{Orientation}

The street connects directly with El-Gish street and end with node which connects it with kafr Essam St., however, the street lacks a proper degree of orientation because of the absence of unique land marks or buildings which important for users to recognize the street easily and determined their directions through its barriers, distances, intersections and directions, making clear image of the street in their minds. So to achieve these goals the street needs to improve its physical elements such as landmarks and improve its important buildings like the governorate mosque, and making vista. Also, add some information elements like maps and signpost.

\subsubsection{Connectivity}

However, there aren't many intersections along the street but the access to the street from El-Gish St. or kafr Essam St. have a clear vision. The street doesn't have many choices for users to take different destination. Also it doesn't offer various types of movement such as cycling, walking, and public transit. To achieve good connectivity to users, the street needs to invite pedestrian network that connect important destinations with other streets, and improve facilities for different kind of movement such as lanes and suitable ground materials and by develop better connection between the clubs and the street.

\subsection{Social Indicators}

\subsubsection{Accessibility}

The street doesn't have enough intersections and good permeability which provide good accessibility in the street. Also street lacks good footpaths, so the accessibility in the 
street can be enhanced by provide wider and better footpaths, clear zone for pedestrians to give users the ability to reach and access all facilities easily.

\subsubsection{Equity}

However the street has many uses and activities which serve all kind of users, but the design and the landscape elements of the street aren't suitable for their actions in it. In addition, Lack of the good facilities for many kinds of users such as pedestrians and people with disability. So there is a need to redesign the street to offer the same opportunities and possibilities to every user in the street by providing suitable access and spaces for all services and activities in it, and using better facilities and streetscape elements which suitable to every kind of user.

\subsubsection{Social relationship}

The street includes various activities which is a good opportunity to make social relationship among the users. But there is a lack of spaces and landscape elements which encourage the interaction between streets' users. This can be improved by provide places to recreational pedestrian activities and offering suitable areas and good conditions to stay, talk, rest and meet were users path on their way, and providing landscape elements and furniture which important to achieve that such as benches, seats, umbrellas, planter boxes, greenery and water elements.

\subsubsection{Safety and comfort}

The street has a medium density of activities and users, but the conflict between different kind of movement including pedestrians, cycling and vehicles decreases the sense of safety and comfort in the street. Therefore the street needs enhancing the sense of safety in it by many urban solutions such as separate paths for every kind of movement and ensure that there are continuous safe footpath along the street and relocate parking in the street as it make unpleasant recreational environment (Figure 6), increasing the density of day and night activities and number of users by inviting more life in to it, provide landscape elements which enhance the sense of safety and comfort along the street such as lighting, signs and suitable ground materials (Figure7).

\subsubsection{Privacy}

There are uses overlaps in the street which effect on the privacy of the street activities. Also, the street hasn't a unique character of its spaces. To enhance this, it should distinguish of its spaces according to the functions and uses by using the different materials and pattern in each space, besides using the barriers between each other.

\subsubsection{Sense of place}

The street lacks of unique identity and distinguish local environment which respects culture aspects, that leads to decrease the sense of place in the street Figure (8). This can be enhanced by improving the buildings façades that frame the street by redesign the frontages of the shops and strength the local architecture character to create unique identity, make strong relationship between the street and the buildings, increase the social activities in the street such as cafes, restaurant, gardens and walkability in addition, 
provide good designed landscape elements with a proper scale and proportion such as furniture, planting which offer a sense of ownership.

\subsection{Visual Indicator}

\subsubsection{Legibility}

Because of the curved shape of the street, it is not obviously clear way for the users. Beside the absence of the buildings with character, the signs and the landmarks, except of the mosque at the intersection with El-Gish St. although it hasn't a distinguishing character. It can be improved by set the signs, memorable architecture, vista, public art and landmarks especially at the intersections.

\subsubsection{Attractiveness and Aesthetics}

The visual image of the street is missing the proper scale, proportion, colors and different aesthetics values which affected the users' sense of the street attractiveness Figure (9). This can be improved by remove out of vertical signs along the street which distorts the buildings details to make the frontages more attractive. Beside enhance the different aesthetics values and the quality of the streetscapes.

\subsubsection{Fine grain:}

The street hasn't enough intersections with a big size blocks which affect negatively the accessibility and enjoying the journey in the street.

Figure (6) Vehicles parking in the street

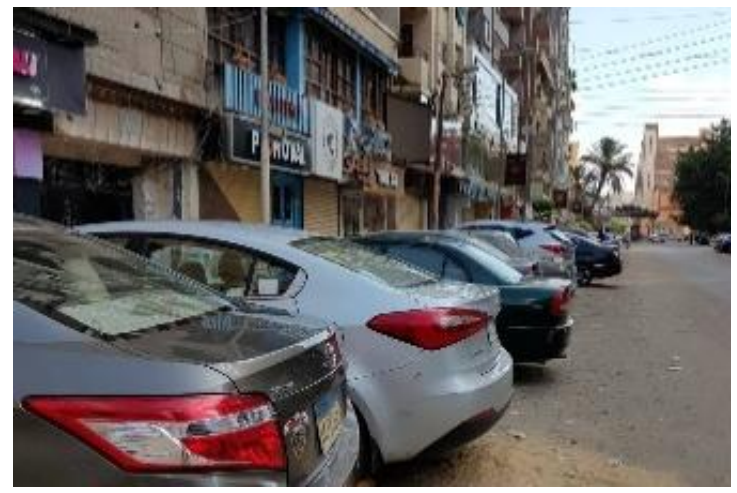

Source: authors 2018
Figure (7) Unsuitable ground materials

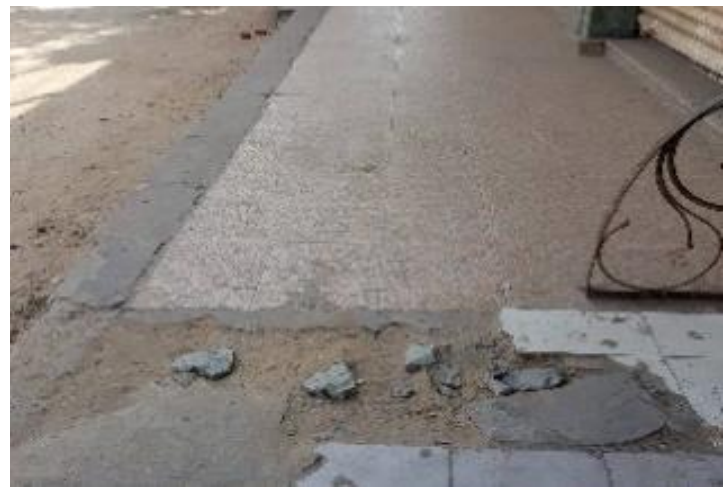

Source: authors 2018 
Figure (8) Lack of unique identity of the street

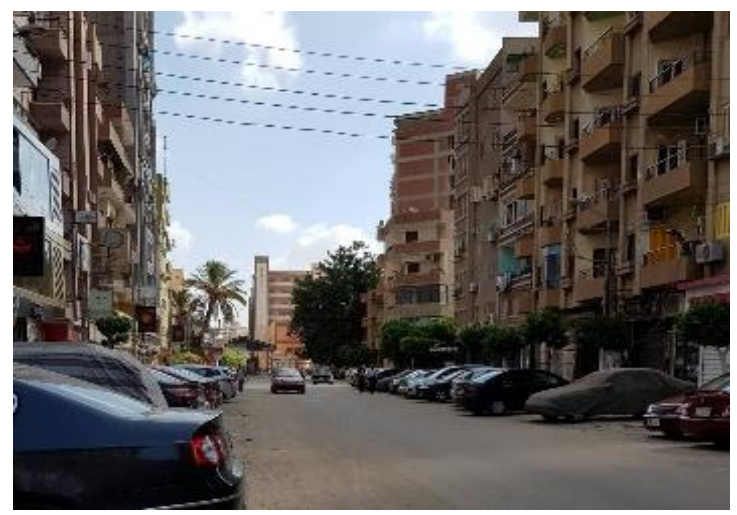

Source: authors 2018
Figure (9) The absence of aesthetics values

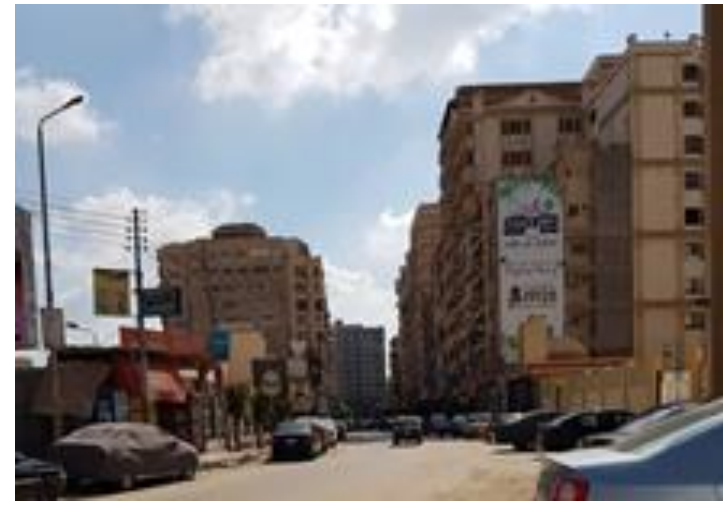

Source: authors 2018

\subsection{Environmental Indicators}

\subsubsection{Health}

The street lacks many standards which important to achieve the urban health such as high density of traffic, shortage of green elements, lack of healthy lifestyle (walk, cycling...etc.) and lack of cleanness that increasing the air, noise and visual pollutions (Figure 10). To enhance the urban health, the street features should encourage healthy lifestyle also provide public transit which decreases the traffic volume, besides increasing the greenery to decrease air pollution and levels of noise.

\subsubsection{Protection}

The street lacks of furniture which protects users from sun radiation, wind and rains and with the absence of the green spaces, all of that important to achieve thermal comfort for users (Figure 11). Also there are no sustainable methods to protect the environmental resources or wastes management (Figure 12). The street needs to provide with sitting areas and spaces protected from sun, wind and rains by using landscape elements such as shades, shelters, protective screens, umbrellas and vegetation. Also reduce the noise level by avoiding microphone Seles people and reducing the music level coming from the shops. In addition, the street needs a better sustainable way to manage the wastes such as provide enough number of waste containers, and adapting many polices to recycling wastes.

\subsection{Economic Indicators}

\subsubsection{Energy consumption}

The volume of the traffic of the street with no public transit lead to increase the energy consumption that can be improved by decrease the traffic volume, and redesign the cycling and pedestrian lanes to present a suitable other options for movement and provide public transit in the street with its stop station. Beside choose the material for the pavements and furniture that don't need higher maintenance requirements like the modular constructions elements. 


\subsubsection{Reduce consumption of material resource}

The choice of street materials doesn't support the use of recycled materials so it is important to redesign the street with using the materials for pavement and other landscape elements from good recycled materials from sustainable natural sources like low energy lighting and porous pavements for traffic lanes.

\subsection{Management Indicator}

\subsubsection{Efficiency of services}

The street hasn't no efficiency maintenance plan that is appear in the degradation of the paving of the different lanes and the bad statue of various street scape elements. So the street needs using durable materials beside establish a good plan for efficiency maintenance.

\subsubsection{Coordinate management}

The urban degradation of the street indicates to absent the holistic management approach which including all the stakeholders in the street. So it is important to establish an integrated coordinate management approach. That identifies the responsibilities for all.

\subsubsection{Community involved}

The interviews with some users appear that there isn't any participation on the management process of the street that leads to state of dissatisfaction. It can be improved by set a plan to involve the community in the management process.

Figure (10) Environmental and visual pollution along the street

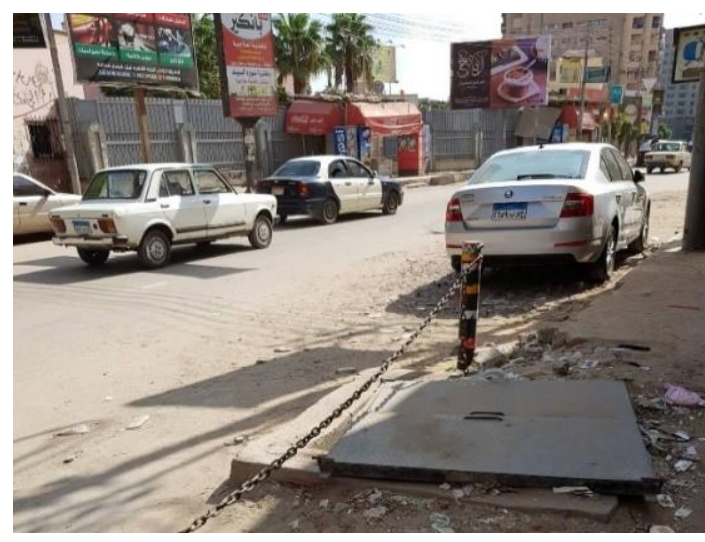

Source: authors 2018
Figure (11) Lake of environmental protection along the street

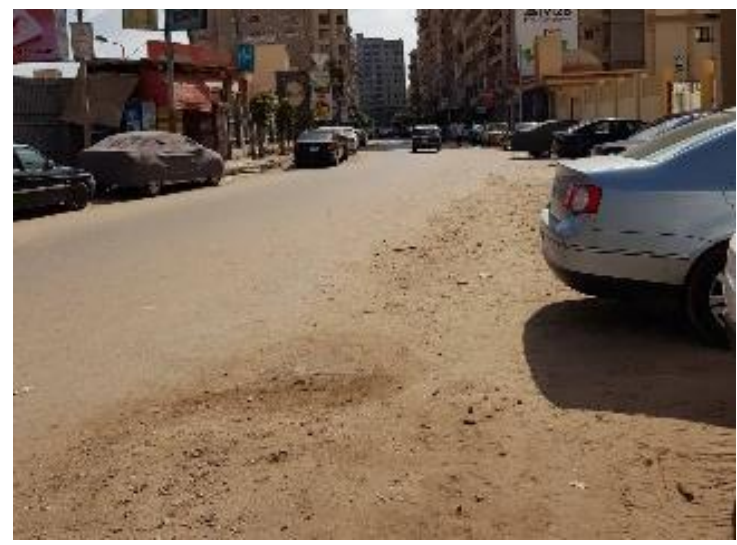

Source: authors 2018 
Figure (11) No sustainable methods to protect the environmental resources or wastes management
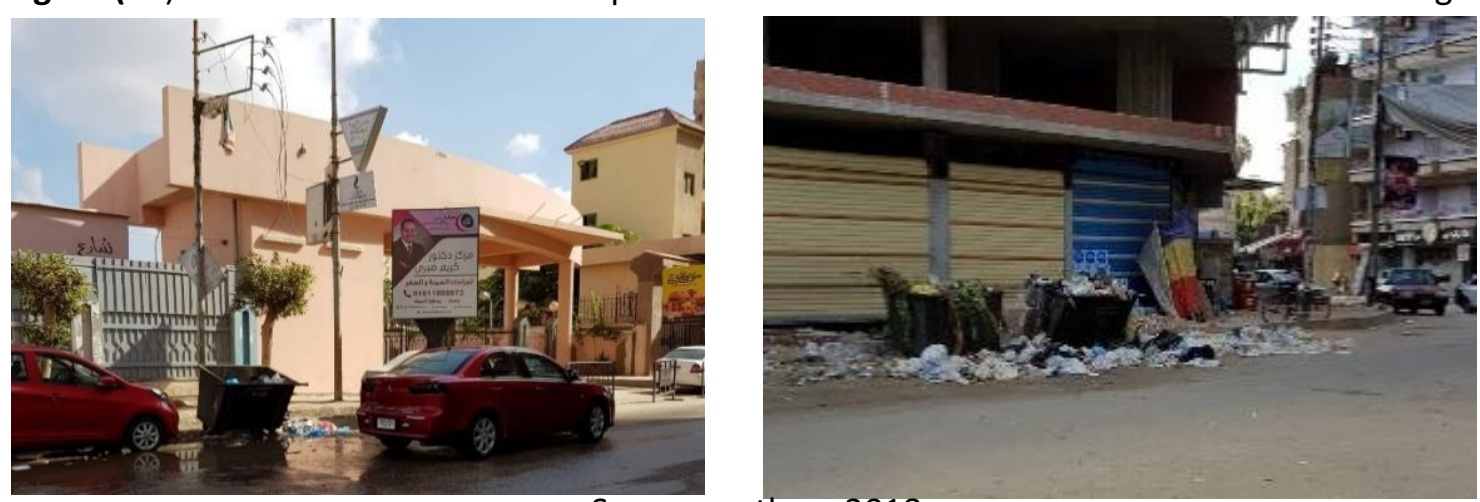

Source: authors 2018

Figure (13) Proposed improvement of El-Moalemeen Club street
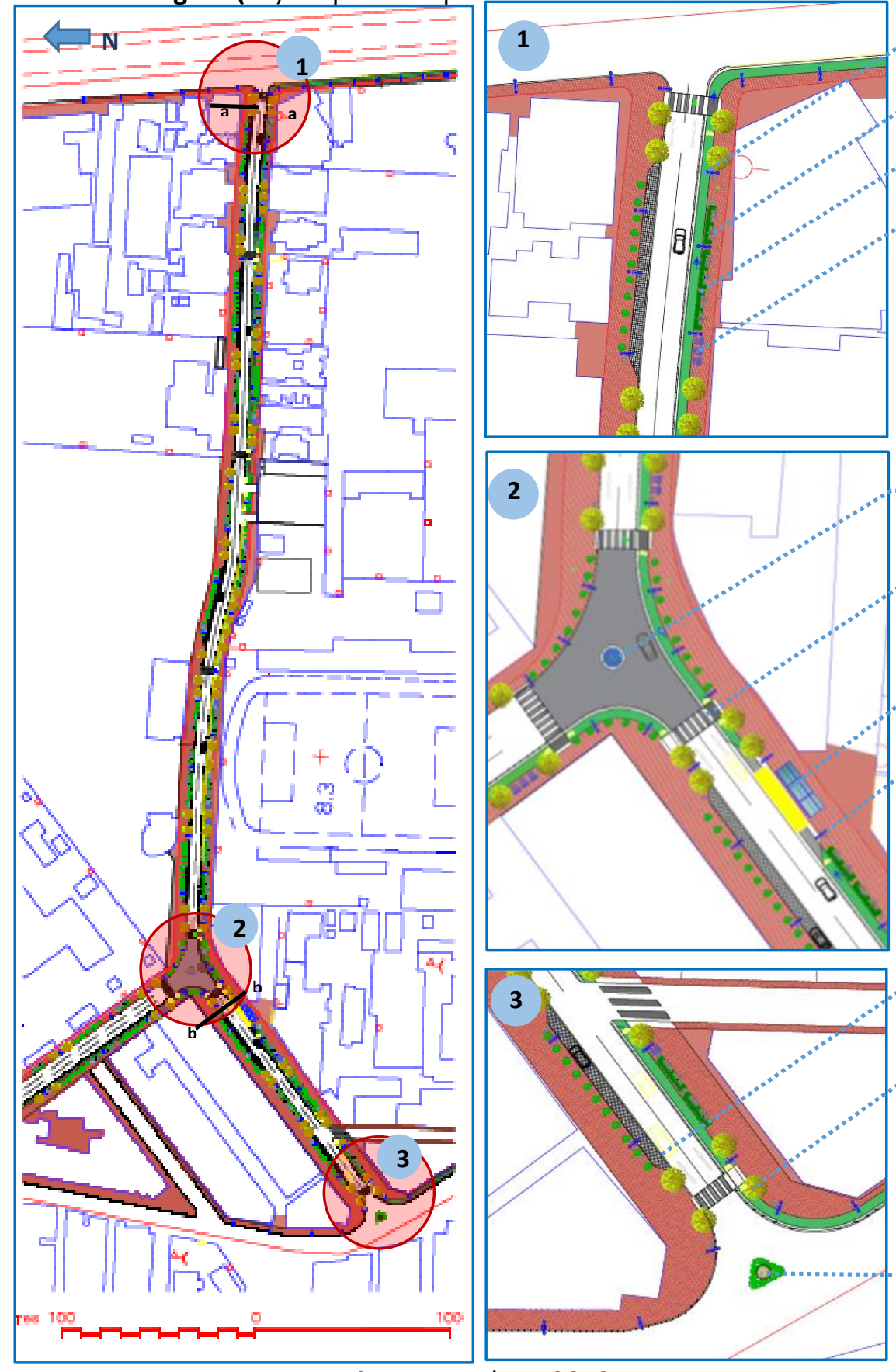

Bike lane
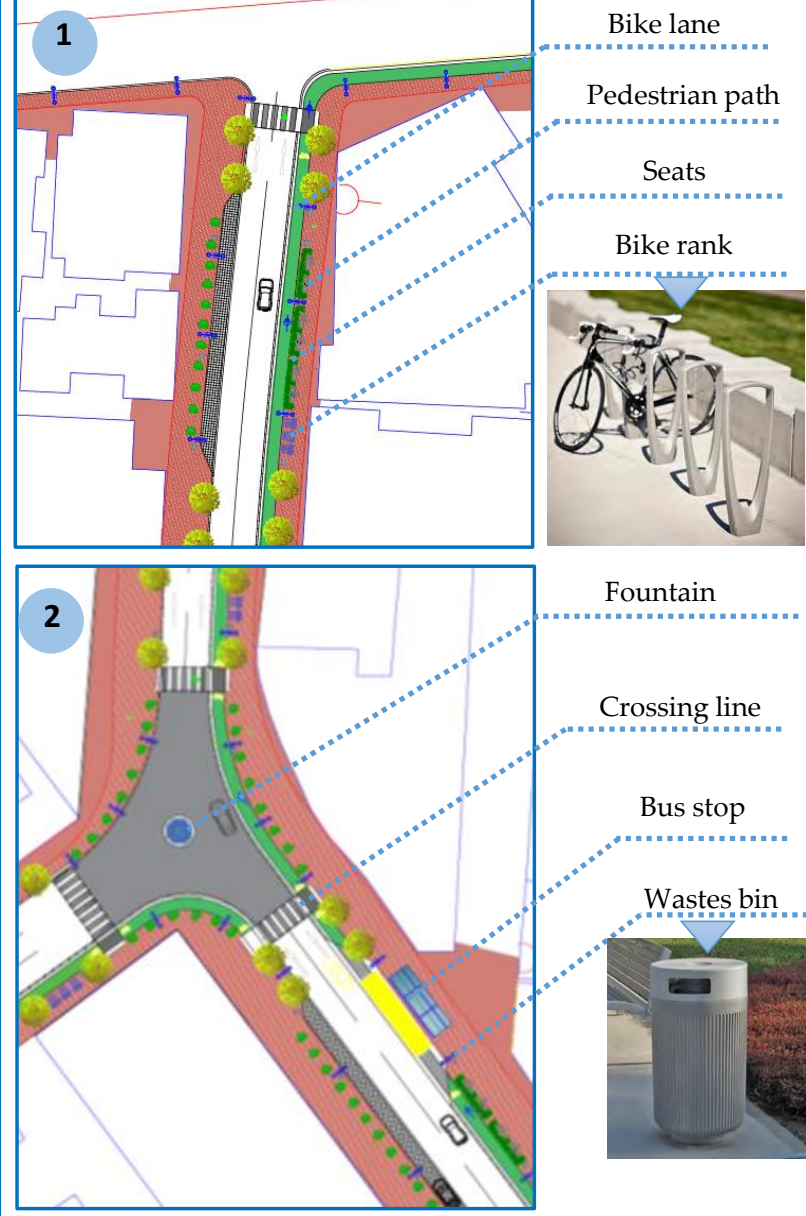

Fountain

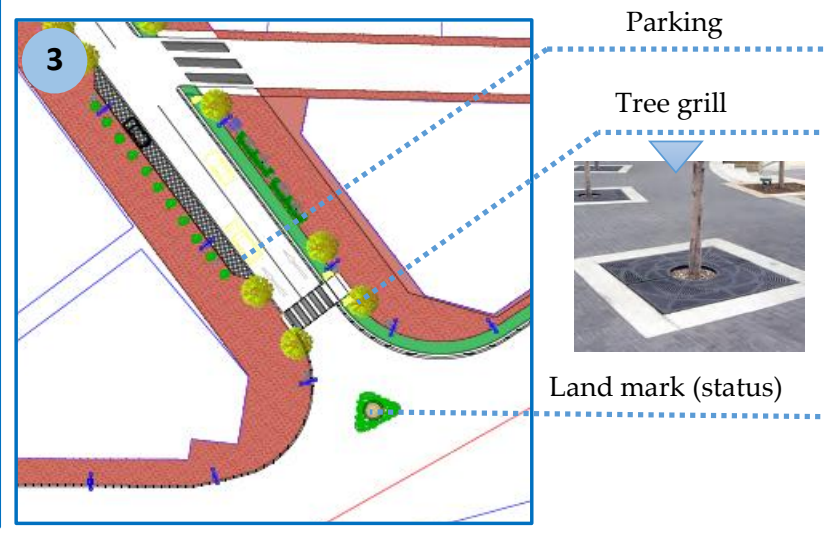


Figure14: Section $a-a$ and section b-b in the El-Moalemeen Club

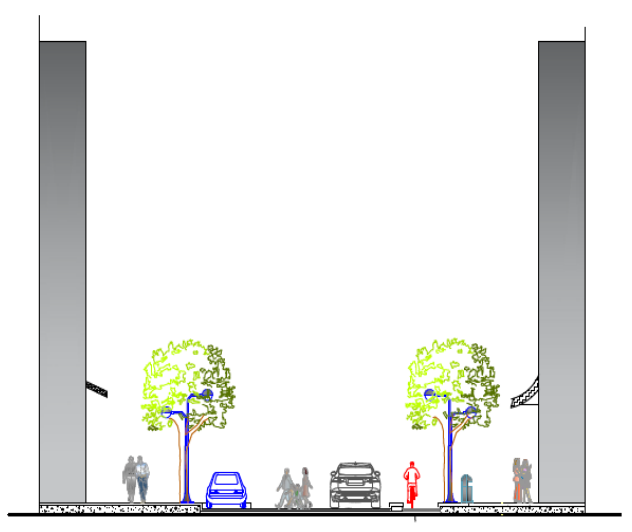

Section a-a

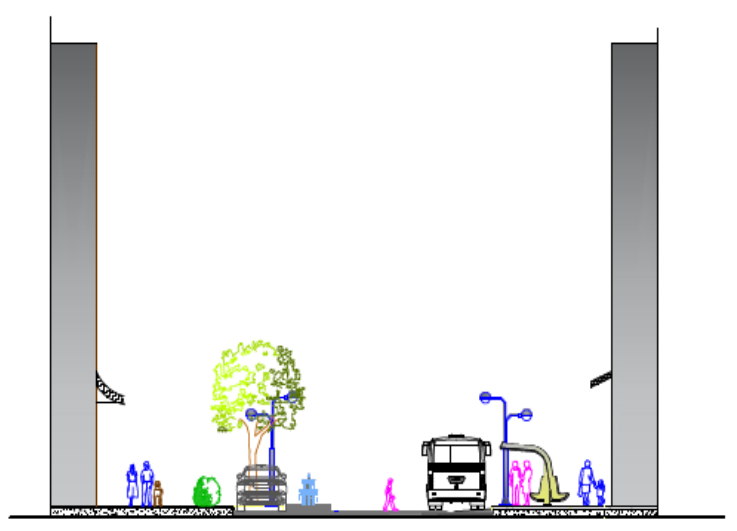

Section b-b

Source: authors 2018

\section{Discussion}

Despite of the good location of the street, its width and the availability of various activities and uses in it, the quality of life for the street users required and hoped from the design of the street, doesn't offer the satisfaction for its users because of the absence of different kinds of movement and their facilities especially the pedestrian and cyclist, Also lack of the good designed spaces for activities to establish more social relationships and sense of place. Besides that, the random using of the different characters and scales of the street boundaries and streetscape elements such as the signs on the frontages, pavements and furniture which effect on the visual image of the street. In addition, many environmental problems like air, noise and visual pollution and lake of use sustainable material and sustainable solutions. All of that lead to a necessary need to improve the street quality by adopting the proposed indicators to develop the street in every aspects such as: providing sufficient spaces for the activities and uses that achieve more social relationships and enhancing their sense of place, redesign the street to includes different kinds movement to achieve safety and comfort for all kinds of users such as provide continuous pedestrian paths and bike lanes, also enhance the green elements and environmental protection to provide shaded areas for users, provide land mark in the nodes and improving the façade of the buildings to enhance the identity of the street, all of this by using sustainable development approach through an integrated management plan.

Figure (13) and Figure (14) showed the proposal improvement for the street considering the proposed indicators of urban quality of life along the street to create livable, sustainable street which achieve the needs of all users' kind and enhance the quality of life for them. 


\section{Conclusions}

The street is the mirror of the public life of any city. By considering the quality of urban life for street it reaches a high degree of the quality of life for all users. It needs to a holistic approach for street design process with perspective of livability, sustainability and quality of urban life indicators. By review the modern urban design trends and approaches and from literatures studies, the research suggests a proposal integrated indicators that assess the urban quality of life through a guideline framework. The integrated indicators are classified in six categories and divided in to sub indicators that corresponds to detailed elements and tools of the evaluation, it includes; physical indicator (mix use activity, mobility, security, orientation, and connectivity) social indicator (accessibility, social relationship, safety and comfort, privacy, and sense of place) visual indicator (legibility, attractiveness and aesthetics, and fine grain) environmental indicator (health and protection), economic indicator (energy consumption, and reduce consumption of material resource) and management indicator (efficiency of services, coordinate management, and community involved). The framework seeks to provide tools and elements for achieve the urban quality of streets. The research applicate the framework guideline checklist to assess a quality of El-moalemeen street in Tanta- Egypt as a case study and set a group of recommendation to improve the street to achieve the quality of urban life.

\section{References}

Amos, Rapoport. (1977). Human Aspects of Urban Form towards a Man Environment Approach to Urban Form and Design. Pergamon press p.77. UK.

Artibise, Yuri. (2012). What is urban fabric? June 26, www.rethinkurban.com

Bevan, T. A., et al. (2007). Sustainable urban Street Design and Assessment. 3rd Urban Street Symposium. P.24-27, USA.

Campbell, A., et al. (1976). The quality of American life: perceptions, evaluations and satisfactions. New York: Russel Sage Foundation.

Cicerchia, A. (1999). Measures of optimal centrality: indicators of city effect and urban overloading. Soc. Indicators Res. 46, P.273-299.

Cohen, Nevin \& Robbins, Paul. Green Cities: An A-to-Z Guide. SAGE Publications, Inc. 2011 p.451.

Cummins, R.A. (2000). Objective and subjective quality of life: an interactive model. Soc. Indicators Res. 52, 55-72.

Darhl, M.Pedersen. (1997). Psychological Functions of Privacy Journal of Environmental Psychology Volume 17, Issue2, P. 147-156

Dashora, L. k, (2007).Visualization of urban Quality of life at neighborhood level in Enchede. Master of Science thesis, International institute for Geo-information science and earth observation, Enschede, Netherland.

Lahart, J.,et al (2013).Design Manual for Urban Roads and Streets. The Department of Transport, Tourism and Sport. Dublin, 
Diener, E., Suh, E. (1997). Measuring Quality of Life: Economic, Social, and Subjective Indicators. Res. 401(2). pp. 189-216.

Diener, E., et al. (1999). Subjective wellbeing: Three Decades of process. Psychological Bulletin, 125(2), P. 276-302.

Duffield, B. Byrne, J. A (2010). Framework for Quality Streetscapes in Moreton Bay Region Place Moreton Bay Street Movement. Moreton Bay Regional Council, South East Queensland, Australia.

Dumbaugh, E. (2005). Safe Streets, Livable Streets. Journal of the American Planning Association. Vol.71, No.3, summer pp.283-300.

Elnaz, G. S., Razaghi, F. (2017). Evaluating Indexes of Life Quality and its Effects on Residential Satisfaction in Dilapidated Residential Areas Case Study: Yaft Abad District, 18th District of Tehran. American Journal of Engineering Research, AJER, Volume-6, Issue-1, pp-14- 20.

Fahy, F. \& Ó Cinnéide, M., (2006). Community-based quality of life indicators for urban areas as derived in Galway City, Ireland. The Sustainable City IV: Urban Regeneration and Sustainability WIT Transactions on Ecology and the Environment, Vol 93, WIT Press, pp. 691702.

Frick, Dieter. (1986). Quality of Urban Life: Social, Psychological, and Physical Conditions. Walter de Gruyter \& Co. Berlin.

Garau, C., Pavan V., M. (2018). Evaluating Urban Quality: Indicators and Assessment Tools for Smart Sustainable Cities. Sustainability journal, 10, 575, Pp.1-18.

Gehl architects, (2009). Downtown Seattle public spaces \& public life. City of Seattle, Seattle Department of Transportation Department of Planning and Development. Sense of place, $p$. 7, P.43.

Gehl, Jan. (1987).Life between Buildings: Using Public Space. Tr. Jo Koch. New York: Van Nostrand Reinhold Company.

Harang, M., (2003). The improving of the Quality of life in Residential areas. The policy tree, April Pp.1-10.

Hardi, P. and Pinter, L. (2006). City of Winnipeg Quality of life Indicators. In Sirjy, M. J., Rahtz, D, and Swain, D. [eds.] community Quality of life indicators: Best casesIl, Springer, Pp.127-176.

Hassell. (2011). LOGAN City Council Street Landscape Strategy. P.5,6, www.logan.qld.gov.au.

ITDP. (2011). Better streets, better cities a guide to street design in urban India Institute for Transportation and Development Policy, www.itdp.org.

Jones, P., et al. (2008). Creating more People-Friendly Urban Streets through 'Link and Place' Street Panning and Design. International Association of Traffic and Safety Sciences IATSS RESEARCH Vol.32 No.1.

Kamp, I. v., et al. (2003). Urban environmental quality and human well-being. Towards a conceptual framework and demarcation of concepts; a literature study. Landscape and Urban Planning 65, Pp.5-18.

Kladivo, P., Halás, M, (2012). Quality of life in an urban environment: a typology of urban environment: A Typology of Olomouc. Questions Geographical 31(2). p. 49-60. 
Konkol, Jonathan R. (2015). Urban Grain, Fostering social and economic diversity through parcelization of large urban development sites. A test case in Seattle's Central District. Master of Architecture University of Washington

Luo, Tong. (2002). The Street Pattern and Social Sustainability in Residential areas. Bartlett School of Planning University College LONDON.

Lynch, K. (1960). The Image of City. The M.I.T. Press.

Mahmoudi, M., Ahmad, F., Abbasi, B. (2015). Livable streets: The effects of physical problems on the quality and livability of Kuala Lumpur streets. Cities 43. P.104-114.

Malczewski, J, (1999). GIS and Multi criteria decision analysis, John Wiley and sons, New York.

Marans, R. W. (2003). Understanding environmental quality through quality of life studies: the 2001 DAS and its use of subjective and objective indicators. Landscape and Urban Planning 65, pp. 73-83.

Marans, R.W., Couper, M. (2000). Measuring the quality of com-munity life: a program for longitudinal and comparative, the Second International Conference on Quality of Life in Cities, vol. 2. Singapore.

Massam, B. H., (2002). Quality of life: Public planning and Privet living. Progress in planning 58 Pp. 141-227.

Merron MP, G., et al., (2007). Communities and local government, Department of transport, Manual for Streets. Thomas Telford Publishing

Mitchell, G., Indicators as tools to guide progress on the sustain-able development pathway. In: Lawrence, R.J. (Ed.), (2000). Sustaining Human Settlement: A Challenge for the New Millennium. Urban International Press, pp. 55-104.

Moghtin, Cliff. Urban Design: Street and Square. Butterworth Architecture Press. Oxford, 1992

Montagomry, J., (1998). Making city: Urbanity, Vitality and Urban Design. Journal of urban design, Vol. 3, No.1. Pp.93-116.

Mostafa, A. M. (2012). Quality of life indicators in value Urban Areas: Kasr Elnile Street in Cairo), Procedia-Social and Behavior-al Sciences 50, 254-270.

Ott, W. R. (1978). Environmental Indices: Theory and Practice, Ann Arbor Science Publishers Inc., Ann Arbor, USA.

Poll, H. F. P. M. V. (1997). The perceived quality of the urban residential environment: a multiattribute evaluation s.n. PhD thesis, University of Groningen/UMCG.

Qawasmeh, R. Identification of the quality of urban life, assessment aspects in residential, neighborhoods in Doha. The Sustainable City IX, Vol. 1 391. WIT Transactions on Ecology and the Environment, WIT Press, (2014) pp.391-402.

Rehan, R. (2013). Sustainable streetscape as an effective tool in sustainable urban design. HBRC Journal 9, P.173-186.

Reza poor, A., et al., (2014). Analysis urban life quality, case study residents of Rostamabad City. American Journal of Engineering Research (AJER), Volume-03, Issue-03, Pp-322-329.

RIVM, Bouwman, A., van Kamp, I., van Poll, R. (Eds.), (2001). Workshop livability. 
Robert, C., et al. (2007). Quality of life: An approach integrating opportunities, human needs, and subjective well-being. Ecological economics, 61, pp. 267-276.

Rudlin, David. Falk, Nicholas. (1999). Building the 21st Century Home: The Sustainable Urban Neighborhood - Edition the Architectural Press uk, p. 155

Serg El Din, H., et al. (2013). Principles of urban Quality of life for a neighborhood. HBRC journal 9, P. 86-92.

Steg, L., Gifford, R. (2008). Sustainable Transport and Quality of Life. Building Blocks for Sustainable Transport, Volume 1by Emerald Group Publishing, Pp.183-202.

The Crafted City. (2011). http://www.craftedcity.com

The United Nation Human settlements program, UNHABITAT.(2008). http://www.unhabitat.org.

Toronto Public Health. Healthy Streets: Evidence Review. City of Toronto. (2014). http://www.toronto.ca/health

Turkoglu, H. D., Marans, R. W. (2009). Quality of urban life. Dos-sier Editorial, ITU A|Z pp. 1-6.

World Health Organization. Report of WHOQOL Focus Group Work. Geneva: WHO (MNH/PSF/93.4). (1993).

Yasaman S. Siavash. (2016). Achieving Urban Resilience: Through Urban Design and Planning Principles. MSc in Spatial Planning. Department of Planning Oxford Brookes University.

http://www.newurbanism.org. 30-7-2018

https://smartgrowthamerica.org. 15-8-2018 